\title{
Burn-in testing in high-power Fully-Aperiodic Large-Pitch-Fiber amplifiers
}

Marie-Alicia Malleville,,${ }^{1,2, *}$ Baptiste Leconte, ${ }^{1}$ William Renard,${ }^{2}$ Romain Dauliat, ${ }^{1,3}$ Rémi du Jeu, ${ }^{1,4}$ Raphaël Jamier, ${ }^{1}$ Anka Schwuchow, ${ }^{3}$ Kay Schuster ${ }^{3}$ and Philippe Roy ${ }^{1}$

${ }^{1}$ Univ. Limoges, CNRS, XLIM, UMR 7252, F-87000 Limoges, France

${ }^{2}$ Eolite Systems, 11 Avenue de Canteranne, 33600 Pessac, France

${ }^{3}$ Leibniz Institute of Photonic Technology, Albert-Einstein-Straße 9, 07745 Jena, Germany

${ }^{4}$ Thales Optronique SA, Laser Solutions Unit, 2 avenue Gay-Lussac, 78995 Elancourt, France

\section{EXTENDED ABSTRACT}

Recently, significant work has been carried out to reach high energy or peak power in fiber lasers. Microstructured fibers with large mode areas (LMA) were developed to address this concern [1,2]. Although these fibers were designed for power scaling while maintaining a single transverse mode propagation, the onset of transverse modal instabilities (TMI) degrades significantly the beam quality because of the re-confinement of one or more higher order modes (HOMs) in the gain area. An original aperiodic pattern made of solid low-index inclusions embedded into the optical cladding was proposed to enhance the HOMs delocalization out of the gain region and thus ensure an effective single-mode emission. Such fibers are called Fully-Aperiodic Large-Pitch Fibers (FA-LPF). An effective single-mode emission can only be obtained, in active FA-LPF, if a zero-refractive index mismatch between the active core and the background cladding material is ensured $(\Delta \mathrm{n}=0)$.

In this work, we realize a first burn-in experiment with a $90 \mathrm{~cm}$-long sample of a $84 \mu \mathrm{m}$ core FA-LPF $(\Delta \mathrm{n}$ of $+8 \times 10^{-5}$ ) in amplification regime. Using a $400 \mathrm{~W}$ pump diode at $976 \mathrm{~nm}$ and seeders providing up to $4 \mathrm{~W}$ of average power at $1030 \mathrm{~nm}$, the power scaling as well as the spatial beam quality and its temporal behavior [3] were investigated in amplifier configuration in two different temporal regimes (nanosecond and picosecond pulses).

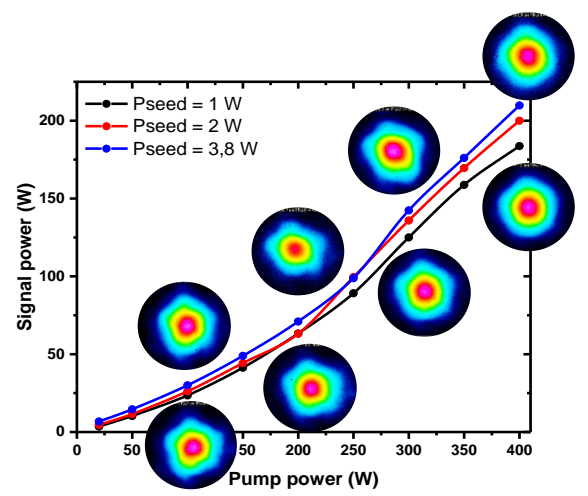

(a)



(b)

Figure 1: (a) Evolution of the output signal power versus pump power for three different seed power levels $\left(\mathrm{P}_{\text {seed }}=1 \mathrm{~W} / 2 \mathrm{~W} / 3.8 \mathrm{~W}\right)$ for the $84 \mu \mathrm{m}$ core fiber $\left(\Delta \mathrm{n}=+8 \times 10^{-5}\right)$ in nanosecond regime. Inset: measured far-field intensity distributions for several signal power levels for $\mathrm{P}_{\text {seed }}=1 \mathrm{~W}$ and $\mathrm{P}_{\text {seed }}=3.8 \mathrm{~W}$. (b) Measured time trace (in yellow) and Fourier spectrum (in green) for an extracted signal power of $210 \mathrm{~W}\left(\mathrm{P}_{\text {seed }}=3.8 \mathrm{~W}\right)$.

In Figure 1 (a), the evolution of the signal power as a function of the incident pump power is presented for the $84 \mu \mathrm{m}$ core FA-LPF tested in nanosecond regime (12 ns pulses for a repetition rate of $250 \mathrm{kHz}$ ). The optical-to-optical efficiency is of $52 \%$ considering the delivered pump power. The measured far-field intensity distributions at the output of the laser are 
reported as insert in Figure 1 (a) for two seed powers $\left(\mathrm{P}_{\text {seed }}=1 \mathrm{~W}\right.$ and $\mathrm{P}_{\text {seed }}=3.8 \mathrm{~W}$ ) and the $\mathrm{M}^{2}$ value was measured lower than 1.3 even at $210 \mathrm{~W}$ of extracted signal power. The TMI power threshold measurement was realized by spatially selecting the center of the beam to maximize the contrast of rapid intensity fluctuations due to the temporal beating of the fundamental mode and the most re-confined $\mathrm{HOM}\left(\mathrm{LP}_{11}\right)$. Considering both $\mathrm{M}^{2}$ values and photodiode time traces (see an example in Figure 1 (b)), one can attest that the TMI phenomenon was not observed even at the maximum average signal power. Indeed, Figure 1 (b) shows the absence of ms-range intensity fluctuations in the time domain.

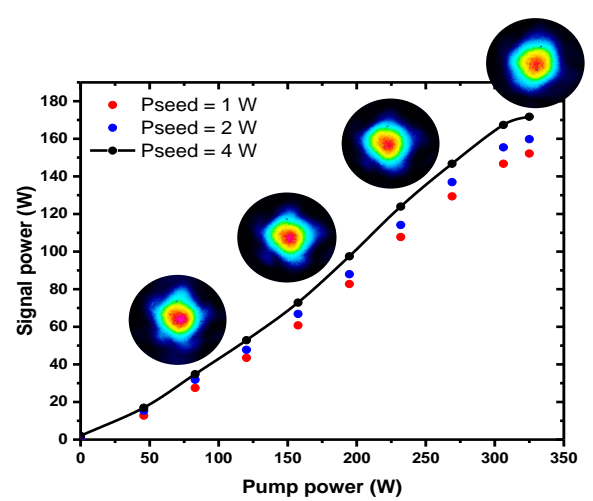

(a)

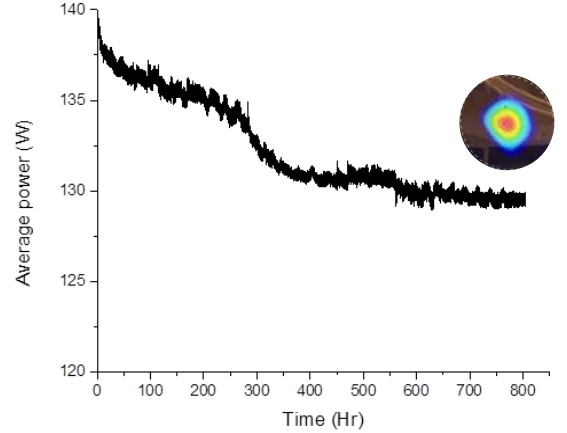

(b)

Figure 2: (a) Evolution of the output signal power versus pump power for three different seed power levels $\left(\mathrm{P}_{\text {seed }}=1 \mathrm{~W} / 2 \mathrm{~W} / 4 \mathrm{~W}\right)$ for the $84 \mu \mathrm{m}$ core fiber in picosecond regime. Inset: measured far-field intensity distributions at several signal power levels for $\mathrm{P}_{\text {seed }}=4 \mathrm{~W}$. (b) Burn-in test over 800 hours realized with the amplifier setup in the picosecond regime. Inset: far-field intensity distribution measured after 800 hours of operation.

In Figure 2 (a), the evolution of the signal power as a function of the incident pump power is presented for the $84 \mu \mathrm{m}$ core FA-LPF tested in picosecond regime ( $50 \mathrm{ps}$ pulses for a repetition rate of $2 \mathrm{MHz}$ ). The maximum extracted signal power achieved $172 \mathrm{~W}$ at $1030 \mathrm{~nm}$, which corresponds to an optical-to-optical efficiency of 53\% considering the incident pump power. The measured far-field intensity distributions at the output of the laser are reported as insert in Figure 2 (a) and the $\mathrm{M}^{2}$ value is lower than 1.4 even at $172 \mathrm{~W}$. The phenomenon of TMI was not observed even after 800 hours of high average power operation in picosecond regime as the beam intensity distribution in insert of Figure 2 (b) can attest. It is worth mentioning that for the same fiber used in laser configuration, the TMI power threshold was determined close to $85 \mathrm{~W}$ [4]. In addition, the signal power decreases from $139 \mathrm{~W}$ to $132 \mathrm{~W}$ until 350 hours, i.e. about $20 \mathrm{~mW} /$ hour, and $5 \mathrm{~mW} /$ hour between 350 hours and 800 hours. This high decrease of the signal power over the time seems to come from a reduction of the seed power with time or a mechanical stability issue in the set-up. For this reason, the same fiber will also be tested in a commercial Eolite Systems laser, which already proved their mechanical stability.

To conclude, TMI were not observed in both nanosecond and picosecond amplification regimes, respectively, even at $210 \mathrm{~W}$ and $172 \mathrm{~W}$ of extracted average signal power. A burn-in test was realized for the first time with a $84 \mu \mathrm{m}$ core fiber in picosecond regime over 800 hours and as the comparison with a commercial laser is impossible in our experimental set-up, we plan to test this fiber in a commercial laser from Eolite Systems.

The authors thank the companies involved in the EATLase project (Eolite Systems, Amplitude Systèmes, Thales Optronics SA, Leukos) as well as the region Nouvelle-Aquitaine for supporting this project through a multi-annual collaboration agreement and financial support. We also thank the ANRT for supporting the thesis of M-A. Malleville and R. du Jeu.

[1] A. Klenke et al., SPIE, Vol 9344, 1, 2015

\section{REFERENCES}

[2] M. Laurila et al., IEEE 978, 2013

[3] H-J. Otto et al., Opt. Exp., 23, 15265-15277, 2015

[4] M-A. Malleville et al., Opt. Lett. 42, 5230-5233, 2017 